\section{Effect of Salicylate on Blood and Liver Xanthine Dehydrogenase of Rats}

MILK and liver xanthine oxidase are inhibited by sodium salicylate in vitro ${ }^{1}$. Bergel et al. ${ }^{2}$ were able to utilize this property for the stabilization of xanthine oxidase by adding salicylate to the process of purification of the enzyme.

Adult white rats of the Wistar strain were used for the determination of the in vivo effect of salicylate on blood and liver xanthine dehydrogenase. Rats were injected intraperitoneally by a single dose of $0.5 \mathrm{mgm}$. of sodium salicylate per gm. body-weight, and xanthine dehydrogenase activity on liver and blood serum determined $4 \mathrm{hr}$. after the injection by methods previously described ${ }^{3}$.

Blood serum of normal rats showed values of $29.0 \pm 6.9 \mu \mathrm{gm}$. formazan $/ \mathrm{ml}$. serum $/ 30 \mathrm{~min}$. at $37^{\circ} \mathrm{C}$. In the injected rats the average value was $40 \cdot 4 \pm 5 \cdot 4 \mu \mathrm{gm}$. formazan $/ \mathrm{ml}$. serum/30 min. These results show an increase of xanthine dehydrogenase activity which is statistically significant, (normal, $t=4 \cdot 2, P<1$ per cent ; injected, $t=7 \cdot 4$, $P<1$ per cent). $24 \mathrm{hr}$. after the injection, this value decreased to $25 \cdot 2 \pm 7 \cdot 0(t=3 \cdot 6, P<2$ per cent $)$. On the other hand, liver from injected rats presented a loss (82.67 per cent inhibition) in xanthine dehydrogenase activity (Table 1).

Table 1. Effect of Salicylate in Rat Liver Xanthine DehydroGENASE*

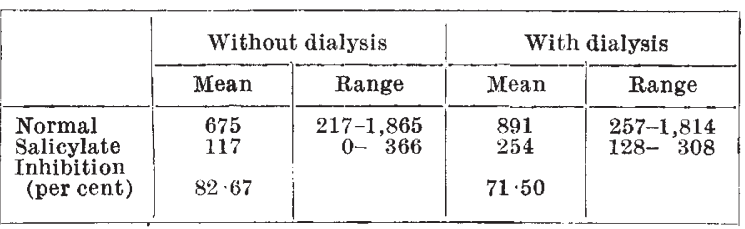

* $\mu \mathrm{gm}$. formazan/gm. dry liver $/ 60 \mathrm{~min}$. at $37^{\circ} \mathrm{C}$.

Since salicylate could be removed from the enzyme by dialysis, with full restoration of the enzyme activity ${ }^{1}$ even after prolonged association ${ }^{2}$, we were interested to know if this in vivo inhibition of rat liver xanthine dehydrogenase by salicylate was also restored by dialysis. Dialysis of liver homogenate against distilled water in the cold gave the results summarized in Table 1.

In vitro experiments with a final concentration of $M / 10$ sodium salicylate showed an inhibition of ratliver xanthine dehydrogenase activity $(60-70$ per cent inhibition) and also of the blood-serum enzyme (50-100 per cent inhibition).

The low restoration of xanthine dehydrogenase activity obtained by dialysis of liver homogenate (Table 1) from injected rats shows that the in vivo inhibition of the xanthine dehydrogenase activity is possibly not only due to a loose bond (split by dialysis) between the salicylate and the enzyme. Definitive liver damage occurs in rats given 400 mgm. of sodium salieylate $/ \mathrm{kgm}$. $/ \mathrm{day}^{4}$. Since the loss of enzyme protein from liver tissue seems to be a general phenomenon which accompanies cell destruction in certain conditions ${ }^{5}$, it seems probable that with the dose used by us $(500 \mathrm{mgm}$. $/ \mathrm{kgm}$.) the flow of the liver xanthine dehydrogenase, which is a soluble protein $^{6}$, to the blood serum results in a decrease of the enzyme activity in liver and consequently an increase of the blood serum xanthine dehydrogenase activity.
We are indebted to Dr. G. G. Villela for his help and advice. This investigation was supported by grants from Conselho Nacional de Pesquisas.

\section{Emitio Mitidieri}

Ottilia R. Affonso

Biochemical Laboratory,

Instituto Oswaldo Cruz, Rio de Janeiro. Dec. 3.

${ }^{1}$ Lutwak-Mann, C., Biochem. J., 36, 706 (1942).

2 Bergel, F., and Bray, R. C., Nature, 178, 88 (1956).

${ }^{3}$ Affonso, O. R., Mitidieri, E., Ribeiro, L.P., and Villela, G. G., Proc. Soc. Exp. Biol. Med., 90, 527 (1955).

"Drill, v. A., "Pharmacology in Medicine" (McGraw-Hill Book Co., Inc., 1958).

${ }^{5}$ Bruns, F., and Neuhaus, J., Arch. Biochem. Biophys., 55, 588 (1955).

' Villela, G. G., Mitidieri, k., and Affonso, O. R., Nature, 175, 1087 (1956).

\section{Re-ingestion in Lepus capensis L. and Ochotona roylei Ogilby}

THE domestic rabbit produces special soft fæcal pellets which are normally taken back into the stomach direct from the anus ${ }^{1,2}$. This behaviour, which has been termed coprophagy, refection ${ }^{2}$ or more appropriately re-ingestion ${ }^{3}$, has been observed in wild rabbits ${ }^{4}$ where it has been shown to follow a regular daily rhythm, beginning about sunrise and ending in the early afternoon ${ }^{3}{ }^{5}$.

Re-ingestion, following a similar rhythm, has since been observed in Lepus europaeus ${ }^{6}$, L. californicus ${ }^{7}$, L. townsendii, $L$. americanus and Sylvilagus transitionalis ${ }^{8}$, and evidence has been reported of re-ingestion in $S$. palustris ${ }^{9}$ and $S$. floridanus ${ }^{10}$.

The present communication reports the occurrence of re-ingestion in another leporid and the first report from the Ochotonidae, thus supporting Watson and Taylor's $s^{6}$ suggestion that re-ingestion is a normal feature of lagomorph biology.

The material was collected from an ablation valley on the northern side of the Barpu Glacier, in the Gilgit Agency of Pakistan, at an altitude of 11,000 $13,000 \mathrm{ft}$. The lower part of the valley was rough grassland where hares (Lepus capensis) were abundant, and higher up this was replaced by a juniper associa. tion (Juniperus turkestanica Korn) growing on boulder banks, where the pikas (Ochotona roylei) lived. Three pikas and 19 hares were shot at different times of the day and nine pikas were trapped at night.

Table 1 groups the 19 hares examined into 2 -hr. periods from $0600 \mathrm{hr}$. to $2000 \mathrm{hr}$. Between $0800 \mathrm{hr}$. and $1400 \mathrm{hr}$. soft fæces were found in the recta, the criterion of active re-ingestion ${ }^{3}$, and in some of these hares amorphous fæcal material was also found in the cardiac end of the stomach. In one hare, which had a tapeworm in the duodenum, a gravid proglottis was found with the frcal material in the stomach. Since no hares were shot at night, these observations

Table 1. INCIDENCE OF RE-INGESTION IN $L$. capensis

\begin{tabular}{|c|c|c|}
\hline Time & No. examined & $\begin{array}{c}\text { No. with soft frecs } \\
\text { in rectum }\end{array}$ \\
\hline 0600 hr. & 1 & 0 \\
0800 & 5 & 0 \\
1000 & 3 & 1 \\
1200 & 2 & 2 \\
1400 & -5 \\
1600 & $-\frac{5}{3}$ & - \\
2000 & $\frac{1}{19}$ & -1 \\
\hline
\end{tabular}

